\title{
Effect of dietary oils on oxidative stress and cytokine production by murine macrophages
}

\author{
R. de la Puerta Vázquez ${ }^{1}$, M. A. Fernández Arche ${ }^{1}$, A. Márquez Martín ${ }^{2}$ and V. Ruiz-Gutierrez ${ }^{2}$ \\ ${ }^{1}$ Dpto Farmacología, Facultad de Farmacia, Universidad de Seville, Spain and ${ }^{2}$ Grupo de Nutrición y Metabolismo \\ Lipídico, Instituto de la Grasa, (CSIC), Seville, Spain
}

Many studies have shown that the nature of the lipid consumed in the diet significantly affects the prevalence of coronary, inflammatory or autoimmune diseases $^{(1,2)}$. The present study was conducted to compare the impact of feeding mice on diets enriched with edible oils $(150 \mathrm{~g} / \mathrm{kg}$ diet; fish oil (FO), olive oil (OVO) and orujo olive oil (ORO)) with that of a basal diet (BD) enriched with $20 \mathrm{~g}$ maize oil/kg on the ability to modulate oxidative reactive species and pro-inflammatory mediator generation by stimulated murine macrophages. Swiss male mice were fed on the different diets for 8 weeks. Diets were formulated according to American Institute of Nutrition (AIN) recommendations ${ }^{(3)}$. Peritoneal macrophages were isolated from these mice and stimulated. Reactive oxygen $\left(\mathrm{O}_{2}{ }^{-}\right.$and $\left.\mathrm{H}_{2} \mathrm{O}_{2}\right)$ and nitrogen $\left(\mathrm{NO}_{2}{ }^{-}\right)$species, PGE 2 , TNF $\alpha$ and IL-6 were measured in the supernatant fractions from $10^{6}$ cells. All test diets down regulated NO generation compared with the BD (Fig.1); in contrast, FO increased $\mathrm{H}_{2} \mathrm{O}_{2}$ generation whereas OVO and ORO group diets significantly inhibited this ROS production compared with the BD. In addition, ORO was able to decrease $\mathrm{O}_{2}{ }^{-}$formation compared with the BD group (Fig.1). Finally, both OVO and FO groups significantly decreased $\mathrm{PGE}_{2}$ and cytokine production (Fig. 2). These results are in agreement with those of other authors in that a diet enriched in olive oil was found to show a protective effect against oxidative stress and inflammation ${ }^{(4,5)}$ and they confirm the preventive anti-inflammatory properties of $\mathrm{FO}^{(6)}$. Moreover, the results provide important additional data about the ability of ORO to prevent oxidative damage to cells.
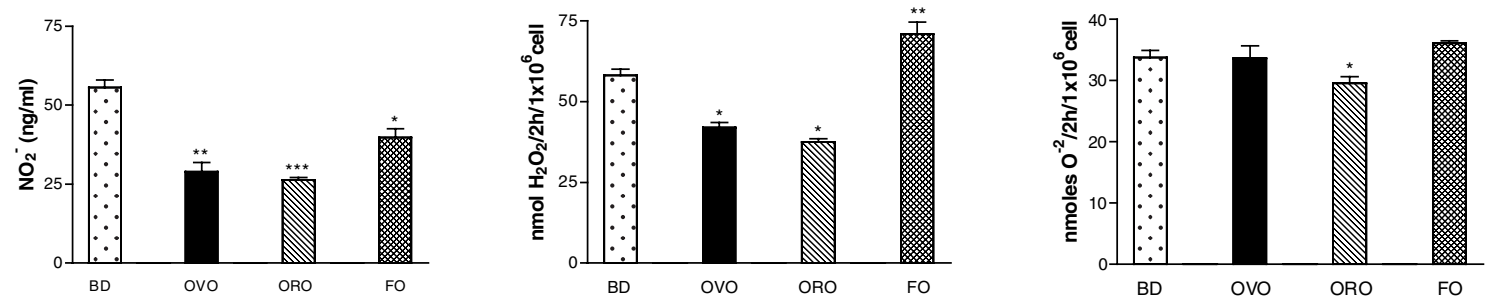

Fig. 1. Reactive oxygen and nitrogen species generated by stimulated murine peritoneal macrophages isolated from mice fed on different oil-enriched diets. Values are means with their standard errors represented by vertical bars for five animals fed on each diet. Mean values were significantly different from those for BD (ANOVA and Student's $t$ test): $* P<0.05, * * P<0.01, * * * P<0.001$.


Fig. 2. $\mathrm{PGE}_{2}$ and cytokines generated by lipopolysaccharide-stimulated murine peritoneal macrophages isolated from mice fed on different oil-enriched diets. Values are means with their standard errors represented by vertical bars for five animals fed on each diet. Mean values were significantly different from those for BD (ANOVA and Student's $t$ test): $* P<0.05, * * P<0.01, * * * P<0.001$.

This study is part of the project AGL2005-00572/AlI, financially supported by the Comision Interministerial de Ciencia y Tecnologia (CICYT).

1. James MJ, Gibson RA \& Cleland LG (2000) Am J Clin Nutr 71, 343-348.

2. Yaqoob P (2003) Curr Opin Clin Nutr Metab Care 6, 133-150.

3. Bieri JG, Stoewsand GS, Briggs GM, Philips RW, Woodward JC \& Knapka JJ (1977) J Nutr 107, 1340-1348.

4. Moreno JJ, Carbonell T, Sanchez T, Miret S \& Mitjavila MT (2001) J Nutr 31, 2145-2149.

5. Perona JS, Arcemis C, Ruiz-Gutierrez V \& Catala A (2005) J Agric Food Chem 53, 730-735.

6. Calder PC (2006) Am J Clin Nutr 86, 1505-1519. 